\title{
Reduction of Silver Ions by Cell Free Extracts of Westiellopsis sp.
}

\author{
P. T. V. Lakshmi, ${ }^{1,2}$ Devi Priyanka, ${ }^{1}$ and A. Annamalai ${ }^{3}$ \\ ${ }^{1}$ Department of Bioinformatics, Bharathiar University, Coimbatore 641 046, India \\ ${ }^{2}$ Phytomatics Laboratory, Centre for Bioinformatics, School of Life Sciences, Pondicherry University, Puducherry 605 014, India \\ ${ }^{3}$ Plant Molecular Biology Laboratory, Department of Biotechnology, School of Biotechnology and Health Sciences, \\ Karunya University, Coimbatore 641 114, India
}

Correspondence should be addressed to P. T. V. Lakshmi; lakanna@bicpu.edu.in

Received 19 September 2014; Accepted 21 December 2014

Academic Editor: Bruce Milthorpe

Copyright (C) 2015 P. T. V. Lakshmi et al. This is an open access article distributed under the Creative Commons Attribution License, which permits unrestricted use, distribution, and reproduction in any medium, provided the original work is properly cited.

\begin{abstract}
Biosynthesis of silver nanoparticles using Westiellopsis sp. (A15), a filamentous cyanobacterium belonging to the family Fischerellaceae, has been demonstrated. Aqueous silver ions $\left(\mathrm{Ag}^{+}\right)$when exposed to the culture filtrate of Westiellopsis were reduced in the solution, which were characterized by biophysical measures utilizing the UV-Vis spectroscopy, scanning electron microscopy (SEM), and FTIR. The nanoparticles exhibited the maximum absorbance at $420 \mathrm{~nm}$ in UV-Vis spectroscopy, while the SEM micrograph revealed that the aggregated nanoparticles vary in size between $20 \mathrm{~nm}$ and $5 \mu \mathrm{m}$. However, the FTIR analysis provided evidence for presence of proteins in the filtrate to be involved in the reduction of silver ions.
\end{abstract}

\section{Introduction}

An important area of research in nanotechnology deals with the synthesis of nanoparticles of different chemical compositions, dimension, and controlled monodispersity. Currently, there is a growing need to develop environmentally benign nanoparticle synthetic processes that are free from toxic chemicals in the synthesis protocol and, as a result, researchers have turned to biological systems employing either microorganisms or plant extracts as a simple and viable alternative to chemical and physical methods. There are many different types of inorganic nanoparticles being synthesized from the biological sources, of which the synthesis of silver nanoparticles has attracted much attention because of their unique shape-dependent optical, electrical, chemical, and antibacterial properties that are widely applied in photographic reactions, catalysis, chemical analysis [1], and prevention of diseases [2]. The first report of live plants synthesizing nanoparticles [3] especially gold nanoparticles (ranging in size from 2 to $20 \mathrm{~nm}$ ) from alfalfa seedlings and subsequently the synthesis of spherical silver nanoparticles from the same plant when exposed to a silver rich solid medium [4] led to the discovery of characterization of extracellularly and intracellularly synthesized silver nanoparticles in many other microbes such as Pseudomonas stutzeri AG259 [5], Escherichia coli, Staphylococcus aureus [6], Phoma sp. 3.2883 [7] and Vibrio cholerae, Pseudomonas aeruginosa, and Salmonella typhus [8].

Although many proofs for synthesizing silver nanoparticle from various biological sources have been reported, not much is being investigated on the cyanobacterial forms which are one of the largest and most important groups of photoautotrophic bacteria on earth that are widely applied in all the fields including biodegradation and bioaccumulation process $[9,10]$. Hence an attempt was made in this direction to screen for the formation of silver nanoparticles in the filamentous cyanobacterium, Westiellopsis sp. (A15) of Fischeralleceae.

\section{Materials and Methods}

2.1. Chemicals. Silver nitrate $\left(\mathrm{AgNO}_{3}\right)$ as analytical grade, citric acid, ferric ammonium citrate, sodium nitrite, magnesium sulphate, calcium chloride, sodium carbonate, EDTA 
disodium salt, zinc sulphate, manganese chloride, copper sulphate, sodium molybdate, and cobalt nitrate were purchased from Himedia Laboratories Pvt., Ltd., while dipotassium hydrogen phosphate and boric acid were purchased from SRL (Mumbai, India).

2.2. Culture Maintenance. Culture of Westiellopsis sp. (A15) was obtained from the Culture Collection of Algae, Centre for Advanced Studies in Botany, University of Madras, Chennai, and was maintained in $\mathrm{BG}_{11}$ medium [11] with citric acid $(0.006 \mathrm{~g} / \mathrm{L})$, ferric ammonium citrate $(0.006 \mathrm{~g} / \mathrm{L})$, sodium nitrite $(1.5 \mathrm{~g} / \mathrm{L})$, magnesium sulphate $(0.075 \mathrm{~g} / \mathrm{L})$, calcium chloride $(0.003 \mathrm{~g} / \mathrm{L})$, sodium carbonate $(0.01 \mathrm{~g} / \mathrm{L})$, EDTA disodium salt $(0.001 \mathrm{~g} / \mathrm{L})$, dipotassium hydrogen phosphate $(0.040 \mathrm{~g} / \mathrm{L})$, and trace metals solution $(1 \mathrm{~mL})$ with the mixture of boric acid $(2.86 \mathrm{~g} / \mathrm{L})$, zinc sulphate $(0.222 \mathrm{~g} / \mathrm{L})$, manganese chloride $(1.81 \mathrm{~g} / \mathrm{L})$, copper sulphate $(0.079 \mathrm{~g} / \mathrm{L})$, sodium molybdate $(0.390 \mathrm{~g} / \mathrm{L})$, and cobalt nitrate $(0.494 \mathrm{~g} / \mathrm{L})$, respectively. The culture flasks were maintained in growth chamber (under 12/12 h light/dark cycle by fluorescent illumination of $40 \mu \mathrm{Em}^{-2} \mathrm{~s}^{-1}$ ) fitted with Frontier digital timer at $27 \pm 1^{\circ} \mathrm{C}$. Gentle shaking of the cultures was done manually every day to reduce the clumping of cells.

2.3. Harvesting of Biomass. The culture was grown for approximately 4-6 weeks to reach the stationary growth phase and was harvested according to the protocol of Lengke et al. [9], where the cells were centrifuged at $8000 \times \mathrm{g}$ for $5 \mathrm{~min}$ and washed with sterile distilled water followed by extensive washing with sterile double-distilled water to remove salts and trace metals from the medium before being used for the experiments.

2.4. Synthesis of Silver Nanoparticles. Typically, $10 \mathrm{~g}$ (wet weight of biomass) after thorough washing with sterile double-distilled water was brought into contact with $100 \mathrm{~mL}$ of sterile double-distilled water for $48 \mathrm{~h}$ at $27^{\circ} \mathrm{C}$ in an Erlenmeyer flask and agitated at $150 \mathrm{rpm}$ on an orbital shaker (ORBITEK) as given by Maliszewska et al. [12]. After the incubation, the cell filtrate was filtered by Whatman filter paper number 1 wherein to $100 \mathrm{~mL}$ of cell filtrate a carefully weighed quantity of silver nitrate was added to yield an overall $\mathrm{Ag}^{+}$ion concentration of $10^{-3} \mathrm{M}$, and the reaction was carried out in the dark [13].

\subsection{Characterization of Silver Nanoparticles}

2.5.1. UV-Vis Spectra Analysis. Surface plasmon resonance of silver nanoparticles was characterized using a UV-visible spectrophotometer (Shimadzu 3600 Spectrophotometer) at the resolution of $1 \mathrm{~nm}$ from 200 to $700 \mathrm{~nm}$ as given by Krishnaraj et al. [14]. After complete reduction of $\mathrm{AgNO}_{3}$ ions by the cell extract, the solution was centrifuged at $14,000 \mathrm{rpm}$ for 30 minutes (SIGMA 3K30, GERMANY) to isolate Ag nanoparticle free from proteins or other bioorganic compounds present in solution. The Ag nanoparticles pellet obtained was redispersed in water and washed (centrifugation and redispersion) with distilled water for 2 times and then air-dried for characterization [15].

2.5.2. SEM Analysis of Silver Nanoparticles. The air-dried silver nanoparticles were subjected to scanning electron microscope (FEI, Japan) which works on the basis of electron beam that typically has an energy range from few $\mathrm{keV}$ to $50 \mathrm{keV}$. The accelerating voltage of the microscope was kept in the range $10-20 \mathrm{kV}$. The samples were made on glass slides which were fixed on aluminium stubs and then allowed to get dry and subsequently a thin layer of gold was coated to customize the sample for conduction. The micrograph was recorded by focusing on clusters of particles [16].

2.5.3. FTIR Spectra Analysis. The FTIR spectrum of the dried nanopowder was recorded by Nicolet 6700 Fourier transform infrared spectroscopy (Nicolet, USA). The sample was prepared by mixing $10 \%$ of the dried nanopowder with $90 \%$ of potassium bromide $(\mathrm{KBr})$ pellet and was characterized with the spectrum ranging between 450 and $4000 \mathrm{~cm}^{-1}$ at a resolution of $4 \mathrm{~cm}^{-1}$ [17].

\section{Results and Discussions}

The biomimetic approaches in search of nanomaterials especially from the organisms that have the ability to remediate the toxic metals via reduction of the metal ions/formation of metal sulphides have provoked the material scientists to explore microorganisms such as bacteria and yeast to prologue as a possible ecofriendly nanofactories [18]. In the present study, an effort made of this kind is solely a new report because although many other forms of cyanobacteria have been investigated for the synthesis or production of different nanoparticles including silver, gold, and platinum, species of Westiellopsis have never been reported so far. Westiellopsis sp. (A15), investigated for the formation of silver nanoparticle, revealed a positive scope for extending research in this organism.

3.1. UV/Vis Spectrum Confirming the Formation of Silver Ions. Upon addition of $\mathrm{Ag}^{+}$ions $(1 \mathrm{mM} \mathrm{AgNO}$ ) into the filtered cell-free culture extract at $27^{\circ} \mathrm{C}$ in the dark, the sample challenged color change from almost colorless to light brown in 10 days and intensively increased with the period of incubation (next 10 days) indicating the formation of silver nanoparticle. Classically, the electric field of an incoming wave induces a polarization of the electrons with respect to much heavier ionic core of silver nanoparticles that results in a net charge difference, which in turn acts as a restoring force to create a dipolar oscillation of all the electrons with the same phase. When the frequency of the electromagnetic field becomes resonant with the coherent electron motion, a strong absorption takes place, which is the origin of the observed colour (brown) whose absorption strongly depended on the particle size, dielectric medium, and chemical surroundings $[19,20]$. However, control (without silver ions) showed no color change of the cell filtrates when incubated in the same conditions (Figures 1(a) and 1(b)). 


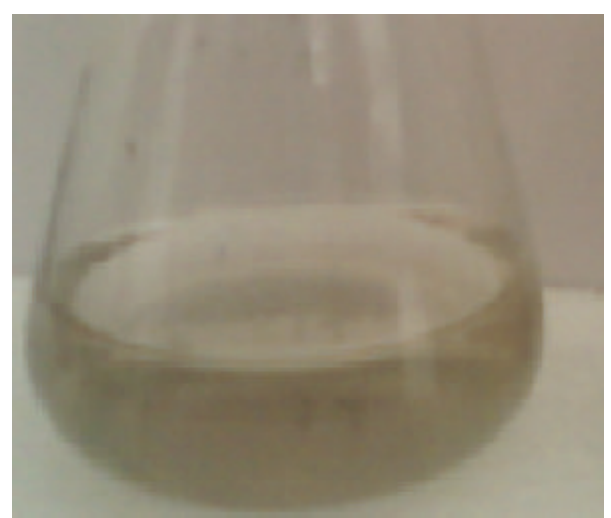

(a)

FIGURE 1: Optical photographs represent the synthesis of silver ions. cyanobacterial cell filtrate treated with $1 \mathrm{mM}$ silver nitrate.

The UV/Vis absorption spectrum [21] resulted in the formation of silver nanoparticles at the visible range of $420 \mathrm{~nm}$ and this may be due to the fact that both the conduction and valence bands would have lain very close to each other permitting the free flow of electrons that might have subsequently given rise to the surface plasmon resonance (SPR) absorption band as evidenced by Taleb et al. [22], Link and El-Sayed [23], and Noginov et al. [19]. Moreover, the long tailing on the large wavelength (Figure 2) could have been due to the small amount of aggregated particles as reported by Maliszewska et al. [12] and proved in the study that the solution containing nanoparticles remained stable for more than four months, with no signs of aggregation or precipitation showing the SPR peak at the same wavelength [24].

3.2. SEM Analysis. The SEM micrographs of nanoparticle obtained in the filtrate were magnified up to $10,000 \mathrm{x}$ at $15 \mathrm{kV}$ and represented the aggregation of silver nanoparticles, which may be due to the sample preparation (including drying) that could have affected its size and shape as reported by Sadowski et al. [25]. However, from the image the particle size could be confirmed to exist below $5 \mu \mathrm{m}$ (Figure 3). In fact, the optical absorption spectra of metal nanoparticles shift to longer wavelengths with increasing particle size. According to $\mathrm{He}$ et al. [26], small spherical nanoparticles $(<20 \mathrm{~nm})$ exhibit a single surface plasmon band. In general, the biosynthesis of silver nanoparticles ranges from 1 to $70 \mathrm{~nm}$ and they have different shapes including spherical, triangular, and hexagonal in forms such as bacteria $[5,6]$, fungi [27$29]$, plants, and plant extract $[4,15,30]$. Thus, the occurrence of spherical nanoparticles in the present study could be attributed to the evidences made by Raut Rajesh et al. [31], according to whom the single surface plasmon peak obtained at $420 \mathrm{~nm}$ even at fourth month could prove the stability of the silver nanoparticles synthesized in the organisms.

3.3. Identification of Functional Groups by FTIR. FTIR characterization reveals the presence of many different functional groups and earlier reports suggested the role of enzymes

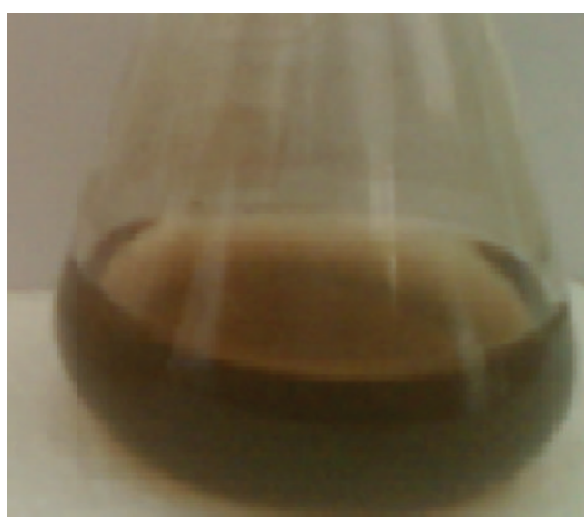

(b)

(a) Control (cyanobacterial cell filtrate without treatment); (b)

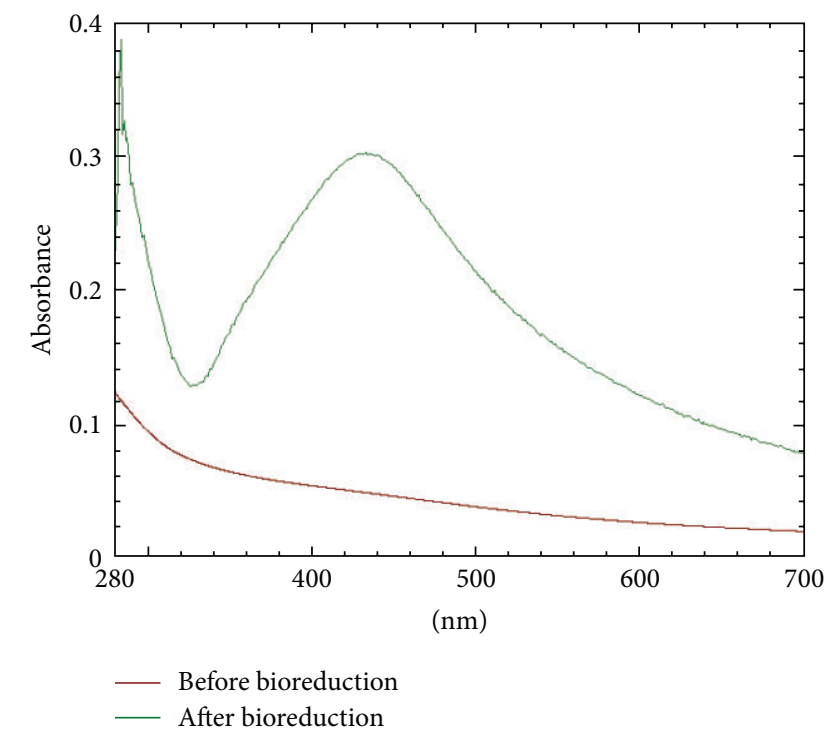

FIGURE 2: The UV/Vis absorption spectra of silver nanoparticles. $\mathrm{nm}$ : wavelength in nanometers (1 unit $=100 \mathrm{~nm})$; Abs: absorbance (1 unit $=0.1$ absorbance unit).

or proteins in the synthesis of silver nanoparticles [32, 33]; accordingly, NADH and NADH-dependent nitrate reductase, when induced by nitrate ions, subsequently reduce silver ions to metallic silver by the electron shuttle enzymatic metal reduction process as observed in the fungus Fusarium oxysporum. Since Westiellopsis sp. (A15) is also known to secrete the cofactor NADH and NADH-dependent nitrate reductase enzyme, this might be responsible for the bioreduction of $\mathrm{Ag}^{+}$to $\mathrm{Ag}^{0}$ and subsequently for the formation of silver nanoparticles because the involvement of nitrate reductase in the production of silver nanoparticles in vitro has already been demonstrated by Kumar et al. [34]. Moreover, in certain cyanobacterial species, several naphthoquinones and anthraquinones with excellent redox properties are reported to be involved in the electron shuttle for metal reduction $[35,36]$, besides the other molecules like polyol, 
TABLE 1: FTIR peaks and their representative functional groups.

\begin{tabular}{|c|c|c|c|}
\hline S. number & FTIR peak & Assigned functional groups & References \\
\hline 1 & 1020 & Stretch vibration of $\mathrm{C}-\mathrm{O}$ & {$[21]$} \\
\hline 2 & 1068,1119 & Stretch vibration of $\mathrm{C}-\mathrm{O}$ and $\mathrm{C}-\mathrm{N}$ stretching vibrations of aliphatic amines & {$[21,22]$} \\
\hline 3 & 1396 & Residual $\mathrm{NO}^{3-}$ & {$[25]$} \\
\hline 4 & 1458 & Symmetric stretching vibrations of $-\mathrm{COO}$ & {$[15]$} \\
\hline 5 & 1496 & $\mathrm{C}-\mathrm{C}$ stretching vibrations of aromatics and asymmetric stretching vibrations of $\mathrm{N}-\mathrm{O}$ & {$[23,24]$} \\
\hline 6 & 1522,1541 & Amide II & {$[24]$} \\
\hline 7 & 1640 & $\mathrm{~N}-\mathrm{H}$ bend and stretching vibrations of $-\mathrm{C}=\mathrm{C}-$ & {$[21]$} \\
\hline
\end{tabular}

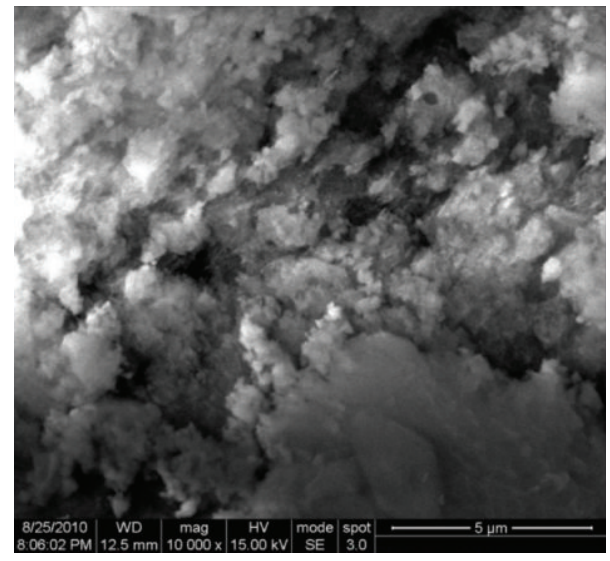

FIGURE 3: Scanning electron micrograph of silver nanoparticles. WD: working distance between the sample surface and the low portion of the lens which should be greater than $4 \mathrm{~mm}(12.5 \mathrm{~mm})$; Mag: magnification at $10000 x$; HV: high voltage $(15 \mathrm{kV})$; Mode: secondary electron (SE) mode.

water-soluble heterocyclic components, and chlorophyll which also influence the reduction of silver ions and capping of silver nanoparticles, respectively [30,37]. Hence, FTIR measurements were carried out to identify the possible biomolecule responsible for the reduction of $\mathrm{Ag}^{+}$ions and capping of the bioreduced silver nanoparticles by cyanobacterial filtrate. Representative spectra of silver nanoparticles (Figure 4) manifested absorption peaks located from less than $400 \mathrm{~cm}$ to $4000 \mathrm{~cm}$ and indicated the specific functional groups. However, the most prominent peaks with important functional groups were located at 1020, 1068, 1119, 1396, 1458, $1496,1522,1541$, and 1640 peaks, respectively, in the regions between 1,000 and $1,800 \mathrm{~cm}^{-1}$ and their corresponding functional groups were identified through the library [17] and were represented in Table 1.

The band at $1020 \mathrm{~cm}^{-1}$ corresponded to the functional group $\mathrm{C}-\mathrm{O}$; similarly, bands at 1068 and $1119 \mathrm{~cm}^{-1}$ corresponded to both $\mathrm{CO}$ stretch vibrations and an aliphatic amine $\mathrm{CN}$ stretch vibration of the proteins $[37,38]$. The absorption peak at $1458 \mathrm{~cm}^{-1}$ may be assigned to symmetric stretching vibrations of -COO- (carboxylate ion) groups of amino acid residues with free carboxylate groups in the protein [15] while the peak at $1496 \mathrm{~cm}^{-1}$ corresponded to both $\mathrm{C}-\mathrm{C}$ stretching vibrations of aromatics and asymmetric stretching vibrations of $\mathrm{N}-\mathrm{O}[30,39]$. The two absorption

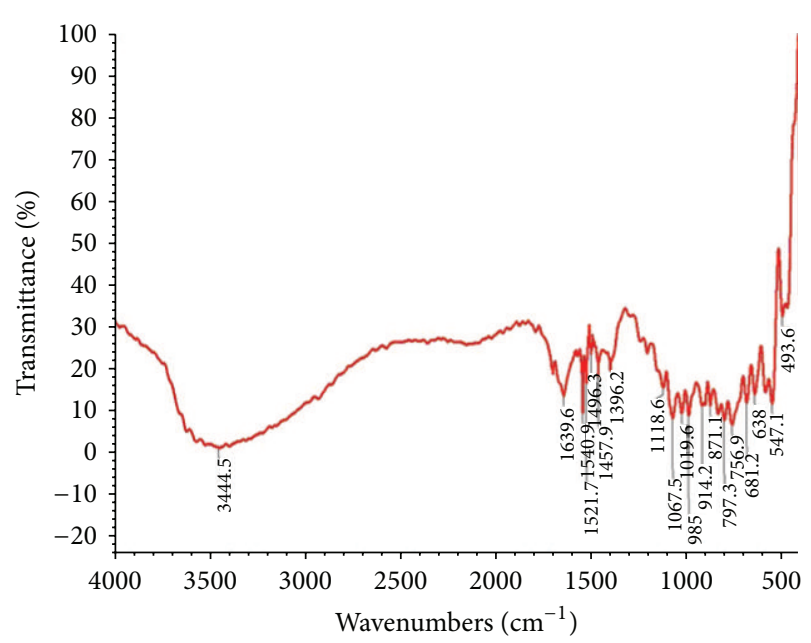

FIGURE 4: FTIR analysis of synthesized silver nanoparticles from Westiellopsis sp. (A.15). Wavenumbers $\mathrm{cm}^{-1}: 1$ unit $=500 \mathrm{~cm}^{-1} ; \%$ transmittance: 1 unit $=10 \%$ transmittance.

peaks located at around 1522 and $1541 \mathrm{~cm}^{-1}$ were assigned to represent amide II of proteins [39] whereas the absorption peak of $1640 \mathrm{~cm}^{-1}$ represented NH bend and the stretching vibrations of $-\mathrm{C}=\mathrm{C}-$ [37]. Moreover, the band at $1396 \mathrm{~cm}^{-1}$ was notably accounted for $\mathrm{NO}^{3-}$ as reported by Luo et al. [40]. The signatures of infrared regions in the electromagnetic spectrum revealed the presence of different functional groups like $\mathrm{C}-\mathrm{N}, \mathrm{C}-\mathrm{O}-\mathrm{O}$, amide linkages, and $-\mathrm{COO}$ that correspond to the formation of amino acid residues and those proteins that bind to nanoparticles as reported by Gole et al. [41], according to whom the free amine groups or cysteine residues in the proteins electrostatically attract the negatively charged carboxylate groups that are present in the extract and therefore contribute to the stabilized proteins. Similarly, functional groups such as $-\mathrm{C}-\mathrm{O}-\mathrm{O}-,-\mathrm{C}-\mathrm{O}-$, and $-\mathrm{C}=\mathrm{C}$ - derived from the heterocyclic compounds ("like proteins") of the cyanobacterial extract could have aided in the capping of ligands to the nanoparticles as reported by Sastry et al. [30] and Sanghi and Verma [38]. Thus, FTIR observation provided an insight into the information that certainly a number of other bioorganic compounds existing in the solution could have participated in the reduction of silver ions and in the stabilization of the nanoparticles formed. 


\section{Conclusion}

The biosynthesis of silver nanoparticles has been demonstrated by reaction of $\mathrm{AgNO}_{3}$ to the cyanobacterial filtrate at $27^{\circ} \mathrm{C}$, where the size of the silver nanoparticle was revealed to be less than $20 \mathrm{~nm}$ on the basis of UV absorption peak. However, the SEM image does not show the clear size and the reason for this could be attributed to error in sample preparation. The bioreduction of $\mathrm{AgNO}_{3}$ could be associated with the released protein from the cyanobacterium into the filtrate as confirmed by FTIR peaks.

\section{Conflict of Interests}

The authors declare that there is no conflict of interests regarding the publication of this paper.

\section{References}

[1] P. Claus and H. Hofmeister, "Electron microscopy and catalytic study of silver catalysts: structure sensitivity of the hydrogenation of crotonaldehyde," Journal of Physical Chemistry B, vol. 103, no. 14, pp. 2766-2775, 1999.

[2] S. Mritunjai, S. Shinjini, S. Prasad, and I. S. Gambhir, "Nanotechnology in medicine and antibacterial effect of silver nanoparticles," Digest Journal of Nanomaterials and Biostructures, vol. 3, pp. 115-122, 2008.

[3] J. L. Gardea-Torresdey, J. G. Parsons, E. Gomez et al., "Formation and Growth of Au Nanoparticles inside Live Alfalfa Plants," Nano Letters, vol. 2, no. 4, pp. 397-401, 2002.

[4] J. L. Gardea-Torresdey, E. Gomez, J. R. Peralta-Videa, J. G. Parsons, H. Troiani, and M. Jose-Yacaman, "Alfalfa sprouts: a natural source for the synthesis of silver nanoparticles," Langmuir, vol. 19, no. 4, pp. 1357-1361, 2003.

[5] T. Klaus, R. Joerger, E. Olsson, and C.-G. Granqvist, "Silverbased crystalline nanoparticles, microbially fabricated," Proceedings of the National Academy of Sciences of the United States of America, vol. 96, no. 24, pp. 13611-13614, 1999.

[6] Q. L. Feng, J. C. Wu, F. Z. Cui, T. N. Kim, and J. O. Kim, “A mechanistic study of the antibacterial effect of silver ions on Escherichia coli and Staphylococcus aureus," Journal of Biomedical Materials Research, vol. 52, no. 4, pp. 662-668, 2013.

[7] J. C. Chen, Z. H. Lin, and X. X. Ma, "Evidence of the production of silver nanoparticles via pretreatment of Phoma sp.3.2883 with silver nitrate," Letters in Applied Microbiology, vol. 37, no. 2, pp. 105-108, 2003.

[8] J. R. Morones, J. L. Elechiguerra, A. Camacho et al., "The bactericidal effect of silver nanoparticles," Nanotechnology, vol. 16, no. 10, pp. 2346-2353, 2005.

[9] M. F. Lengke, M. E. Fleet, and G. Southam, "Biosynthesis of silver nanoparticles by filamentous cyanobacteria from a silver(I) nitrate complex," Langmuir, vol. 23, no. 5, pp. 26942699, 2007.

[10] R. Brayner, H. Barberousse, M. Hemadi et al., "Cyanobacteria as bioreactors for the synthesis of $\mathrm{Au}, \mathrm{Ag}, \mathrm{Pd}$, and Pt nanoparticles via an enzyme-mediated route," Journal of Nanoscience and Nanotechnology, vol. 7, no. 8, pp. 2696-2708, 2007.

[11] M. M. Allen, "Simple conditions for growth of unicellular bluegreen algae on plates," Journal of Phycology, vol. 4, no. 1, pp. 1-4, 1968.
[12] I. Maliszewska, K. Szewczyk, and K. Waszak, "Biological synthesis of silver nanoparticles," Journal of Physics: Conference Series, vol. 146, no. 1, Article ID 012025, 2009.

[13] F. A. Mohammed, K. Balaji, M. Girilal, R. Venkatesan, and P. T. Kalaichelvan, "Mycobased synthesis of silver nanoparticles and their incorporation into sodium alginate films for vegetable and fruit preservation," Journal of Agricultural and Food Chemistry, vol. 57, no. 14, pp. 6246-6252, 2009.

[14] C. Krishnaraj, E. G. Jagan, S. Rajasekar, P. Selvakumar, P. T. Kalaichelvan, and N. Mohan, "Synthesis of silver nanoparticles using Acalypha indica leaf extracts and its antibacterial activity against water borne pathogens," Colloids and Surfaces B: Biointerfaces, vol. 76, no. 1, pp. 50-56, 2010.

[15] S. S. Shankar, A. Ahmad, and M. Sastry, "Geranium leaf assisted biosynthesis of silver nanoparticles," Biotechnology Progress, vol. 19, no. 6, pp. 1627-1631, 2003.

[16] K. Kalimuthu, R. Suresh Babu, D. Venkataraman, M. Bilal, and S. Gurunathan, "Biosynthesis of silver nanocrystals by Bacillus licheniformis," Colloids and Surfaces B: Biointerfaces, vol. 65, no. 1, pp. 150-153, 2008.

[17] A. Ingle, M. Rai, A. Gade, and M. Bawaskar, "Fusarium solani: a novel biological agent for the extracellular synthesis of silver nanoparticles," Journal of Nanoparticle Research, vol. 11, no. 8, pp. 2079-2085, 2009.

[18] G. Southam and T. J. Beveridge, "The occurrence of sulfur and phosphorus within bacterially derived crystalline and pseudocrystalline octahedral gold formed in vitro," Geochimica et Cosmochimica Acta, vol. 60, no. 22, pp. 4369-4376, 1996.

[19] M. A. Noginov, G. Zhu, M. Bahoura et al., "The effect of gain and absorption on surface plasmons in metal nanoparticles," Applied Physics B: Lasers and Optics, vol. 86, no. 3, pp. 455-460, 2007.

[20] R. Das, S. S. Nath, D. Chakdar, G. Gope, and R. Bhattacharjee, "Preparation of silver nanoparticles and their characterization," Nanotechnology, vol. 5, pp. 1-6, 2009.

[21] B. J. Wiley, S. H. Im, Z.-Y. Li, J. McLellan, A. Siekkinen, and Y. Xia, "Maneuvering the surface plasmon resonance of silver nanostructures through shape-controlled synthesis," The Journal of Physical Chemistry B, vol. 110, no. 32, pp. 15666-15675, 2006.

[22] A. Taleb, C. Petit, and M. P. Pileni, "Optical properties of selfassembled 2D and 3D superlattices of silver nanoparticles," Journal of Physical Chemistry B, vol. 102, no. 12, pp. 2214-2220, 1998.

[23] S. Link and M. A. El-Sayed, "Optical Properties and ultrafast dynamics of metallic nanocrystals," Annual Review of Physical Chemistry, vol. 54, pp. 331-366, 2003.

[24] M. Fu, Q. Li, D. Sun et al., "Rapid preparation process of silver nanoparticles by bioreduction and their characterizations," Chinese Journal of Chemical Engineering, vol. 14, no. 1, pp. 114$117,2006$.

[25] Z. Sadowski, I. H. Maliszewska, B. Grochowalska, I. Polowczyk, and T. Koźlecki, "Synthesis of silver nanoparticles using microorganisms," Materials Science, vol. 26, no. 2, pp. 419-424, 2008.

[26] R. He, X. Qian, J. Yin, and Z. Zhu, "Preparation of polychrome silver nanoparticles in different solvents," Journal of Materials Chemistry, vol. 12, no. 12, pp. 3783-3786, 2002.

[27] P. Mukherjee, A. Ahmad, D. Mandal et al., "Fungus-mediated synthesis of silver nanoparticles and their immobilization in the mycelial matrix: a novel biological approach to nanoparticle synthesis," Nano Letters, vol. 1, no. 10, pp. 515-519, 2001. 
[28] N. Durán, P. D. Marcato, O. L. Alves, G. I. H. de Souza, and E. Esposito, "Mechanistic aspects of biosynthesis of silver nanoparticles by several Fusarium oxysporum strains," Journal of Nanobiotechnology, vol. 3, article 8, 2005.

[29] K. C. Bhainsa and S. F. D'Souza, "Extracellular biosynthesis of silver nanoparticles using the fungus Aspergillus fumigatus," Colloids and Surfaces B: Biointerfaces, vol. 47, no. 2, pp. 160-164, 2006.

[30] M. Sastry, A. Ahmad, M. I. Khan, and K. Rajiv, "Biosynthesis of metal nanoparticles using fungi and actinomycete," Current Science, vol. 85, no. 2, pp. 162-170, 2003.

[31] W. Raut Rajesh, R. Lakkakula Jaya, S. Kolekar Niranjan, D. Mendhulkar Vijay, and B. Kashid Sahebrao, "Phytosynthesis of silver nanoparticle using Gliricidia sepium (Jacq.)," Current Nanoscience, vol. 5, no. 1, pp. 117-122, 2009.

[32] J. I. Nirmal Kumar, B. Anubhuti, and K. A. Manmeet, "Chronic toxicity of the triazole fungicide tebuconazole on a heterocystous, nitrogen-fixing rice paddy field cyanobacterium, Westiellopsis prolifica Janet," Journal of Microbiology and Biotechnology, vol. 20, no. 7, pp. 1134-1139, 2010.

[33] A. Ahmad, P. Mukherjee, S. Senapati et al., "Extracellular biosynthesis of silver nanoparticles using the fungus Fusarium oxysporum," Colloids and Surfaces B: Biointerfaces, vol. 28, no. 4, pp. 313-318, 2003.

[34] S. A. Kumar, M. K. Abyaneh, S. W. Gosavi et al., "Nitrate reductase-mediated synthesis of silver nanoparticles from $\mathrm{AgNO}_{3}$," Biotechnology Letters, vol. 29, no. 3, pp. 439-445, 2007.

[35] D. K. Newman and R. Kolter, "A role for excreted quinones in extracellular electron transfer," Nature, vol. 405, no. 6782, pp. 94-97, 2000.

[36] M. Sturdy, A. Krunic, S. Cho, S. Franzblau, and J. Orjala, "Eucapsitrione, an anti-mycobacterium tuberculosis anthraquinone derivative from the cultured freshwater cyanobacterium Eucapsis sp." Journal of Natural Products, vol. 73, no. 8, pp. 1441-1443, 2010.

[37] J. Huang, Q. Li, D. Sun et al., "Biosynthesis of silver and gold nanoparticles by novel sundried Cinnamomum camphora leaf," Nanotechnology, vol. 18, no. 10, Article ID 105104, 2007.

[38] R. Sanghi and P. Verma, "Biomimetic synthesis and characterisation of protein capped silver nanoparticles," Bioresource Technology, vol. 100, no. 1, pp. 501-504, 2009.

[39] V. Bansal, D. Rautaray, A. Bharde et al., "Fungus-mediated biosynthesis of silica and titania particles," Journal of Materials Chemistry, vol. 15, no. 26, pp. 2583-2589, 2005.

[40] L. B. Luo, S. H. Yu, H. S. Qian, and T. Zhou, "Large-scale fabrication of flexible silver/cross-linked poly(vinyl alcohol) coaxial nanocables by a facile solution approach," Journal of the American Chemical Society, vol. 127, no. 9, pp. 2822-2823, 2005.

[41] A. Gole, C. Dash, V. Ramakrishnan et al., "Pepsin-gold colloid conjugates: preparation, characterization, and enzymatic activity," Langmuir, vol. 17, no. 5, pp. 1674-1679, 2001. 

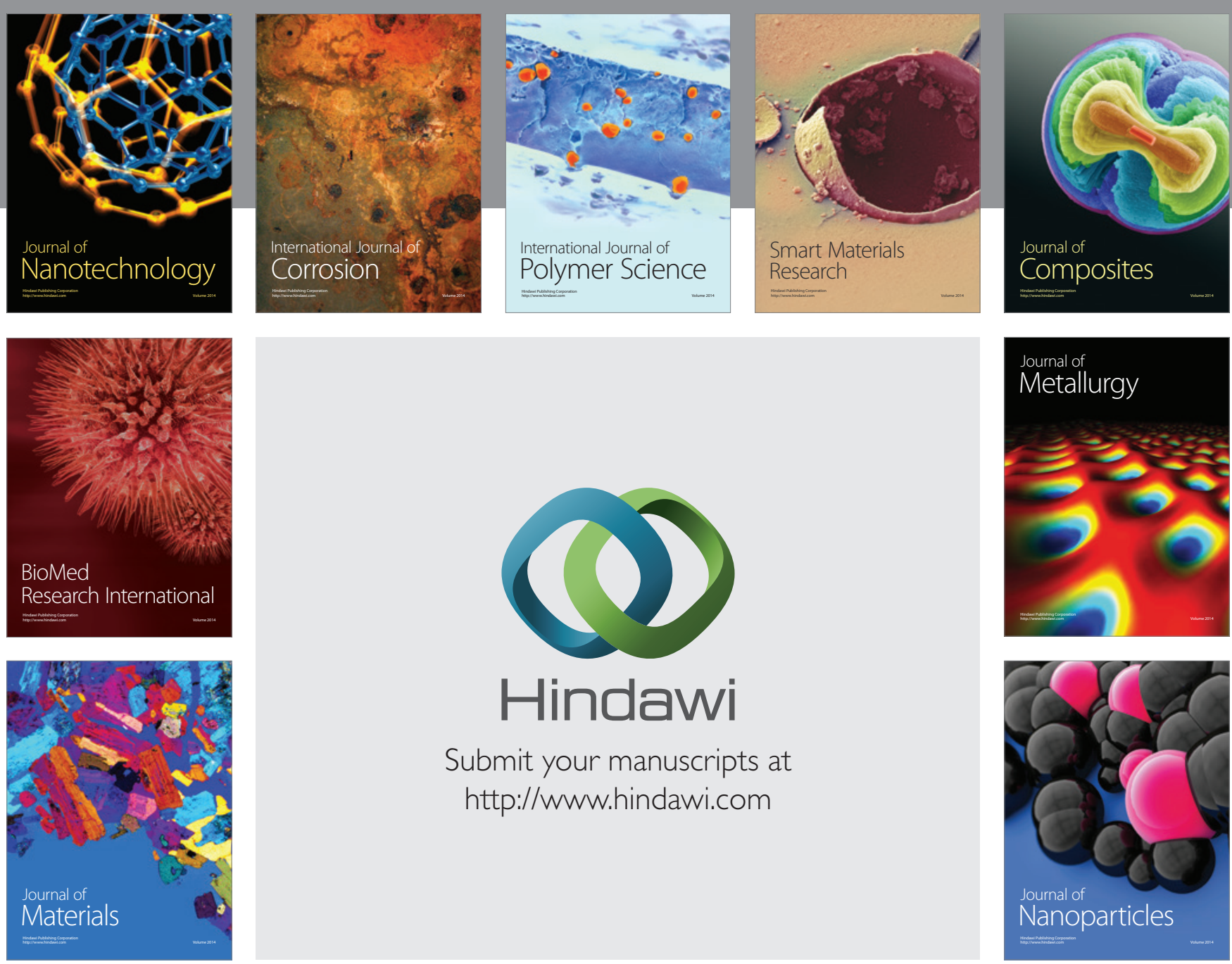

Submit your manuscripts at http://www.hindawi.com
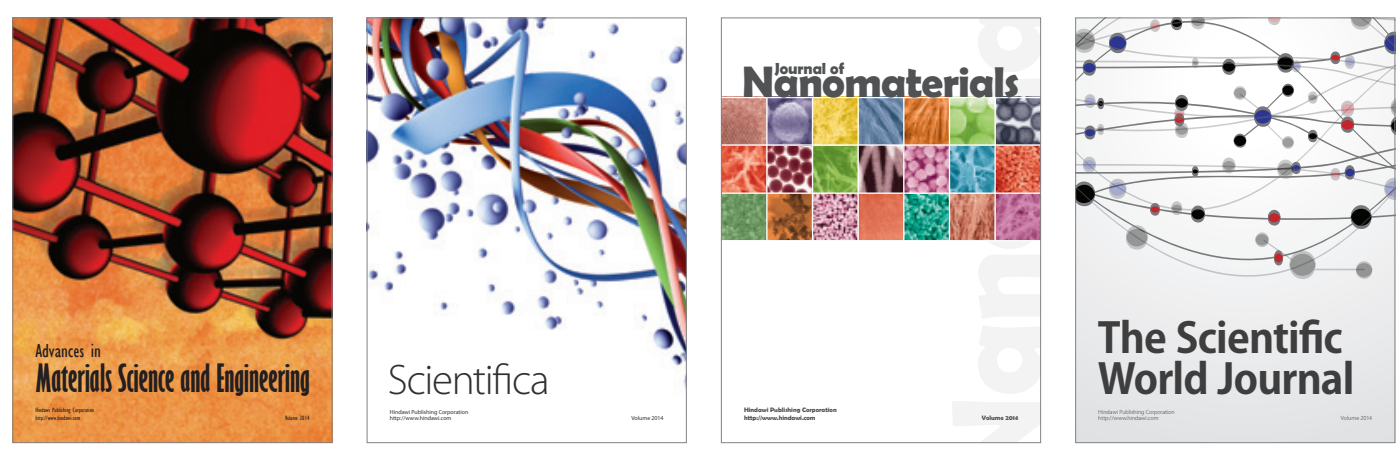

\section{The Scientific World Journal}
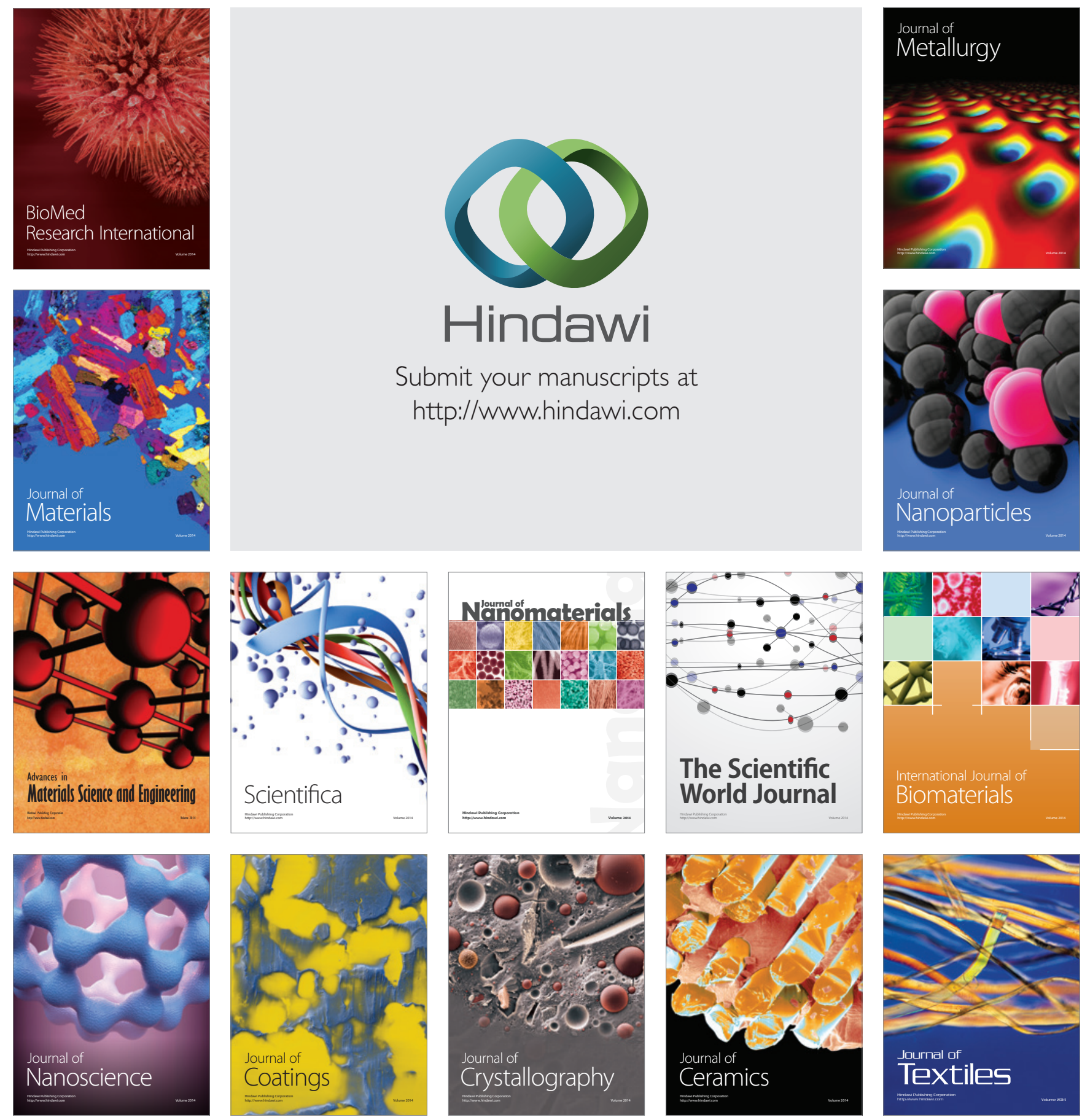